\title{
Investigation on Strength and Pore Structure of Supersulfated Cement Paste
}

\author{
Shuhua LIU*, Lu WANG \\ State Key Laboratory of Water Resources and Hydropower Engineering Science, Wuhan University, Wuhan, 430072, \\ China \\ crossref http://dx.doi.org/10.5755/j01.ms.24.3.18300
}

Received 02 June 2017; accepted 12 October 2017

\begin{abstract}
The compressive strength and pore microstructure of supersulfated cement (SSC) pastes with different kinds of gypsum, different treatments on phosphogypsum and different fineness, and ordinary Portland cement, slag Portland cement were investigated. The results indicate that phosphogypsum SSC performs better compared to anhydrite and dihydrate gypsum SSC for strength development, especially at late hydration age. For long curing age, burned at $500{ }^{\circ} \mathrm{C}$ for phosphogypsum is better than neutralized with $4 \%$ lime in SSC. The higher the fineness, the higher the cement hydration degree, especially at early age, more hydration products such as ettringite and C-S-H form, and the strength improves to some extent. Compared to ordinary Portland cement and slag Portland cement, phosphogypsum-based SSC has the lowest strength at early age, while the strength growth rate increases over curing time. The paste strength mainly depends on the average pore size but porosity. SSC paste contains more harmless pore, which is beneficial for pore structure and strength.

Keywords: supersulfated cement paste; strength; pore structure; fineness; cementitious system.
\end{abstract}

\section{INTRODUCTION}

Cement, as one of the most important cementitious materials in construction, has been praised by many people. However, with the improvement of people's environmental protection consciousness, cement which is the product of an energy-intensive industry and is responsible for large emissions of carbon dioxide has aroused the world's reflection $[1-4]$. How to reduce energy consumption and environmental pollution? The most direct solution is to use less or no cement. So, more and more mineral admixtures are used as supplementary cementitious materials to replace part of cement or even a large part [5-9]. SSC is a good example.

SSC contains less clinker cement or no clinker cement, and it is mainly composed of ground granulated blast furnace slag and takes gypsum as sulfate activator, a little amount of clinker as alkali activator and its main hydration products are $\mathrm{C}-\mathrm{S}-\mathrm{H}$ and ettringite. The component ratio is usually as follows: $75 \%-85 \%$ of slag; some sulfates (anhydrite, dihydrate gypsum or phosphogypsum), about $10 \%-20 \%$; and $1 \%-5 \%$ of alkaline composition [10-12]. In this paper, three different kinds of gypsums such as anhydrite, dihydrate gypsum and phosphogypsum are taken to study their different influences on setting and hardening of cements, as well as the pore structure and compressive strength. At the same time, phosphogypsum as sulfate activator, the treatment on gypsum is another factor. Burned at $500{ }^{\circ} \mathrm{C}$ and neutralized with $4 \%$ lime powder may make difference on their hydration. According to the previous researches [13-16], the fineness is also an influence factor on hydration rate and pore structure. As for SSC, the higher fineness may increase its early hydration. SSC is not common in China, and there is no standard for it. So if it will be widely used in projects to replace existing cement, it must be comparable with common cement, such as ordinary Portland cement and slag Portland cement.

So, in this paper, the following four aspects of SSC, gypsum type, treatment on phosphogypsum, fineness and different types of cements, will be studied and discussed between compressive strength and pore microstructure, to provide certain reference for future research.

\section{EXPERIMENTAL}

\subsection{Raw materials}

This paper involved 9 kinds of cements, which are anhydrite-based SSC (SSC1), dihydrate gypsum-based SSC (SSC2), phosphogypsum-based SSC (SSC3), burned phosphogypsum-based SSC (SSC4), neutralized phosphogypsum-based SSCs with specific surface area of $355 \mathrm{~m}^{2} / \mathrm{kg}$ (SSC5), $445 \mathrm{~m}^{2} / \mathrm{kg}$ (SSC6), $518 \mathrm{~m}^{2} / \mathrm{kg}$ (SSC7), ordinary Portland cement (PO), slag Portland cement (PS) with $50 \%$ slag, and their chemical compositions are shown in Table 1. The 9 cements are prepared by mixing the different components in the laboratory. All SSCs contain much higher $\mathrm{SO}_{3}$ and lower $\mathrm{CaO}$ comparing with $\mathrm{PO}$ and PS. All phosphogypsum-based cements (from SSC3 to SSC7) contain higher content $\mathrm{P}_{2} \mathrm{O}_{5}$ than other cements. The chemical compositions of 3 kinds of gypsums are listed in Table 2 and their SEM micrographs are shown in Fig. 1. Table 2 shows the specific surface area of the 9 kinds of cements and from Table 2, except for SSC5 and SSC7, the fineness of all cements is about the same, and they can be comparable at the same scale.

\footnotetext{
* Corresponding author. Tel.: +86-27-68772233; fax: +86-27-68772310.

E-mail address: shliu@whu.edu.cn (S. Liu)
} 
Table 1. Chemical compositions of the 9 cements, mass $\%$

\begin{tabular}{|c|c|c|c|c|c|c|c|c|c|c|}
\hline Samples & $\mathrm{Na}_{2} \mathrm{O}$ & $\mathrm{MgO}$ & $\mathrm{Al}_{2} \mathrm{O}_{3}$ & $\mathrm{SiO}_{2}$ & $\mathrm{P}_{2} \mathrm{O}_{5}$ & $\mathrm{SO}_{3}$ & $\mathrm{~K}_{2} \mathrm{O}$ & $\mathrm{CaO}$ & $\mathrm{Fe}_{2} \mathrm{O}_{3}$ & $\mathrm{LOSS}^{2}$ \\
\hline SSC1 & 0.23 & 6.17 & 11.11 & 25.25 & 0.02 & 13.17 & 0.56 & 41.18 & 1.09 & 1.22 \\
\hline SSC2 & 0.26 & 6.21 & 11.34 & 25.91 & 0.04 & 12.23 & 0.62 & 40.84 & 1.28 & 1.27 \\
\hline SSC3 & 0.22 & 5.19 & 11.43 & 26.42 & 0.33 & 12.27 & 0.59 & 41.02 & 1.24 & 1.29 \\
\hline SSC4 & 0.21 & 4.99 & 11.21 & 26.01 & 0.38 & 14.01 & 0.57 & 40.62 & 0.83 & 1.17 \\
\hline SSC5 & 0.23 & 4.93 & 10.87 & 25.63 & 0.40 & 13.42 & 0.60 & 41.45 & 1.18 & 1.29 \\
\hline SSC6 & 0.24 & 5.12 & 11.25 & 26.16 & 0.35 & 12.39 & 0.60 & 41.40 & 1.25 & 1.24 \\
\hline SSC7 & 0.24 & 5.38 & 11.63 & 25.81 & 0.34 & 12.24 & 0.57 & 41.25 & 1.18 & 1.36 \\
\hline PO & 0.08 & 1.36 & 5.41 & 20.25 & 0.11 & 3.96 & 1.12 & 63.09 & 3.24 & 1.38 \\
\hline PS & 0.21 & 4.25 & 10.21 & 26.47 & 0.07 & 3.33 & 0.87 & 51.27 & 2.05 & 1.27 \\
\hline
\end{tabular}

Table 2. Chemical compositions of 3 kinds of gypsums (mass \%) and specific surface area of the 9 cements $\left(\mathrm{m}^{2} / \mathrm{kg}\right)$

\begin{tabular}{|c|c|c|c|c|c|c|c|c|c|c|}
\hline Samples & $\mathrm{Na}_{2} \mathrm{O}$ & $\mathrm{MgO}$ & $\mathrm{Al}_{2} \mathrm{O}_{3}$ & $\mathrm{SiO}_{2}$ & $\mathrm{P}_{2} \mathrm{O}_{5}$ & $\mathrm{SO}_{3}$ & $\mathrm{~K}_{2} \mathrm{O}$ & $\mathrm{CaO}$ & $\mathrm{Fe}_{2} \mathrm{O}_{3}$ & $\mathrm{LOSS}^{2}$ \\
\hline Phosphogypsum & 0.05 & 0.27 & 0.55 & 5.31 & 1.03 & 48.91 & 0.22 & 42.3 & 0.47 & 0.89 \\
\hline Anhydrite & - & 0.92 & 0.14 & 0.79 & - & 55.63 & 0.03 & 42.11 & 0.08 & 0.30 \\
\hline Dihydrate gypsum & - & 0.03 & - & - & - & 56.49 & - & 43.46 & 0.01 & 0.01 \\
\hline
\end{tabular}

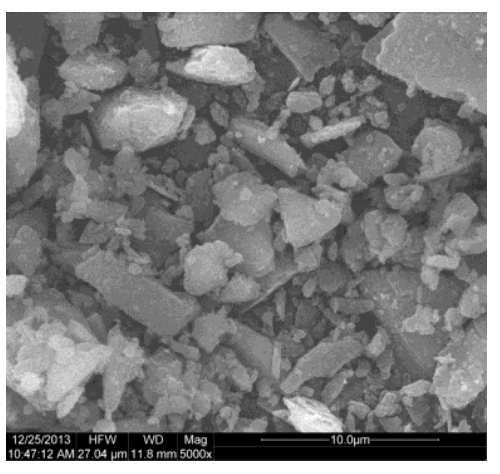

a

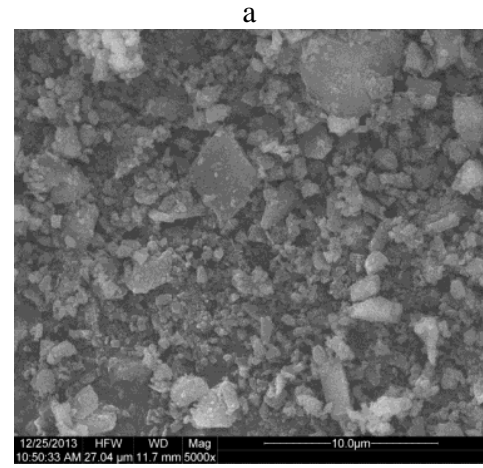

b

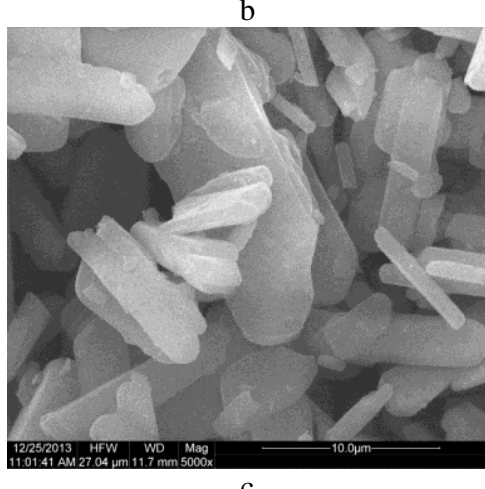

c

Fig. 1. SEM micrographs $\times 5000$ of 3 kinds of gypsum: $\mathrm{a}$-phosphogypsum; $\mathrm{b}$-anhydrite; $\mathrm{c}$-dihydrate gypsum

\subsection{Specimens preparation}

$40 \times 40 \times 40 \mathrm{~mm}^{3}$ paste specimens with $\mathrm{w} / \mathrm{b}$ ratio 0.40 were prepared and cured at room temperature till stipulated age of 3, 7, 28 and 90 days.

\subsection{Test methods}

The compressive strength of the pastes on different curing age is tested by a compression testing machine (WAY-2000), which is produced by Shangyu Machinery Factory, and the specific test procedure is referred to GB/T17671-2005, Method of testing cement-determination of strength.

The chemical compositions of the 9 cements presented in Table 1 were measured on Axios advanced X-ray fluorescence (XRF) instrument, produced by Japanese Rigaku Corporation. In order to determine the pore structure, some patches of the paste specimens were taken out by breaking at 90 days, and then packed into the ampere bottle, which was filled up with absolute ethyl alcohol to stop the hydration. Pore structure was determined by Mercury Injection Pore Apparatus (MIP) whose model is Auto Pore IV (9500), produced by American Micromeritics Instrument Corporation, to calculate pore sizes between $30 \AA$ and $0.9 \mathrm{~mm}$, and pressures is between 0.20 and 60,000.00 psi (about 413.76 MPa to $1.38 \mathrm{kPa}$ ).

\section{RESULTS AND DISCUSSION}

\subsection{Effect of gypsum type}

Three types of gypsum, anhydrite, dihydrate gypsum and phosphogypsum were used in this paper, which produced three different cement-based materials, anhydrite-based SSC (SSC1), dihydrate gypsum-based SSC (SSC2) and phosphogypsum-based SSC (SSC3). Different raw materials can make up different paste specimens with different properties. As shown in Fig. 2, 
the compressive strength development was influenced by gypsum type.

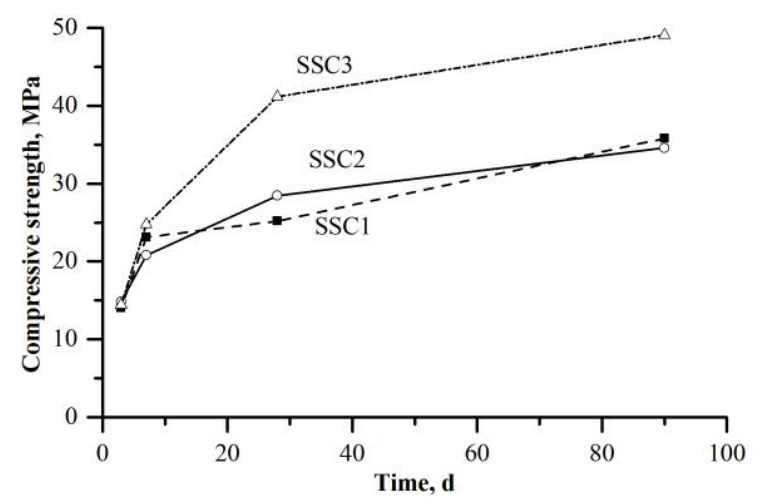

Fig. 2. Influence on compressive strength of gypsum type in SSC

At 3 and 7 days, the compressive strength of the three SSCs was almost the same, especially at the age of 3 days, about $14 \mathrm{MPa}$. At the age of 28 days, the compressive strength of SSC3 was about $41 \mathrm{MPa}$, while the strength of SSC1 and SSC2 was $25 \mathrm{MPa}$ and $28 \mathrm{MPa}$ respectively. Increasing to 90 days, the compressive strength of SSC3 reached to $49 \mathrm{MPa}$, much higher than that of SSC1 and SSC2 which are about $36 \mathrm{MPa}$ and $35 \mathrm{MPa}$ respectively. So, phosphogypsum-based SSC performs better in strength especially at later. At early age, low compressive strength may be caused by the retarding effects of $\mathrm{P}_{2} \mathrm{O}_{5}$ in phosphogypsum and phosphogypsum itself, which can slow the early hydration [10]. Lots of pores are not full filled by the hydration products. Therefore, more hydration products have enough pores to generate at later, which improve the microstructure of paste.

Fig. 3 shows the cumulative pore size distribution curves and the pore volume differential curves of SSC1, SSC2 and SSC3. From Fig. 3, we can get the porosity, average pore size and the pore size classification with $50 \mathrm{~nm}$, and the results are shown in Fig. 4.

From Fig. 4 a, the porosity of SSC3 is the biggest while its average pore size is the smallest. It has been demonstrated that the porosity is smaller, the structure is denser, and the compressive strength is higher [17-19]. The compressive strength of SSC3 in Fig. 1 was the highest, however its porosity was the biggest, which seemed to be conflicted with the traditional theory. The compressive strength of the paste probably mainly depends on average pore size. Fig. $4 \mathrm{~b}$ shows the aperture classification with $50 \mathrm{~nm}$ of the three SSC pastes. The amount of harmless pore with aperture smaller than $50 \mathrm{~nm}$ is important for microstructure development and strength growth of paste. The higher the amount of harmless pore was expected to develop much denser microstructure of the paste [20].

The calculation value $n$ is defined as the quantity of harmless pore with pore size smaller than $50 \mathrm{~nm}$ to the whole pore ratio is as follows [20],

$n=a /(a+b) \times 100 \%$,

Where, $a$ is the quantity of harmless pore with pore size smaller than $50 \mathrm{~nm}$; $b$ is the quantity of harmless pore with pore size bigger than $50 \mathrm{~nm}$.

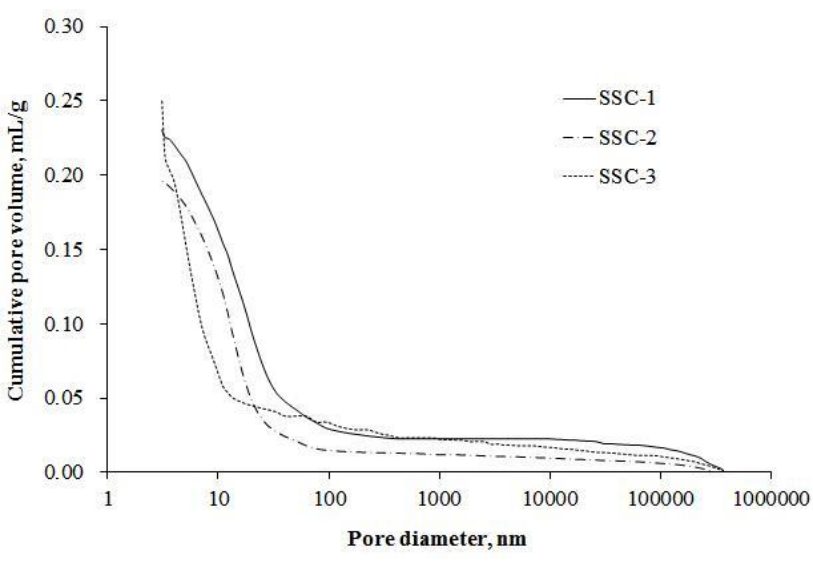

a

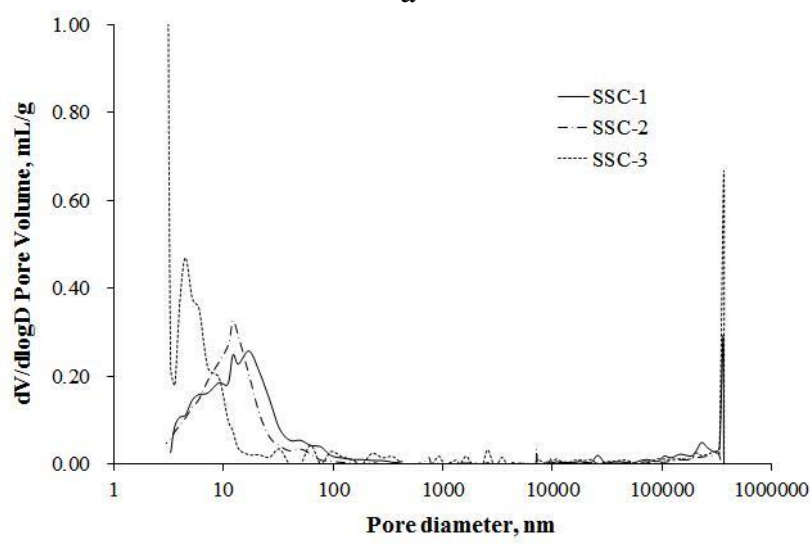

b

Fig. 3. The cumulative and differential pore size distribution curves of SSC1, SSC2 and SSC3

According to the formula above, $n_{\mathrm{SSC} 1}$ is $0.1881 /(0.1881+0.0423)=81.64 \%, \quad n_{\mathrm{SSC} 2}$ is $0.1755 /(0.1755+0.0212)=89.22 \%$ and $n_{\mathrm{SSC} 3}$ is $0.2132 /(0.2132+0.0379)=84.91 \%$. As the results of value $n$, the highest value is $n_{\mathrm{SSC} 2}$. Among all the SCC specimens, the pore volume of harmless pore of SSC3 is bigger than that of SSC1 and SSC2, and SSC3 has the smallest average pore size, which can support the strength development in Fig. 2.

\subsection{Effect of phosphogypsum treatment methods}

The phosphogypsum can be burned at $500{ }^{\circ} \mathrm{C}$ or neutralized with $4 \%$ lime powder to prepare the two different SSCs, i.e., burned phosphorgypsum-based SSC (SSC4) or neutralized phosphogypsum-based SSC (SSC6). At the same time, SSC3 is taken as the comparison.

The influence on compressive strength development of phosphogypsum treatment methods in SSC are shown in Fig. 5. The strength development of SSC3 whose phosphogypsum without any treatments is relatively flat and smaller than that of SSC4 and SSC6. So after treatment of phosphogypsum in SSC, the compressive strength can increase at different extent. The treatment method of phosphogypsum in SSC is different; the result of compressive strength is different, too.

At the age from 3 days to 28 days, the increase of compressive strength of SSC6 comparing with SSC3 is higher than that of SSC4, while from the age of 28 days to 90 days, the result is opposite. 

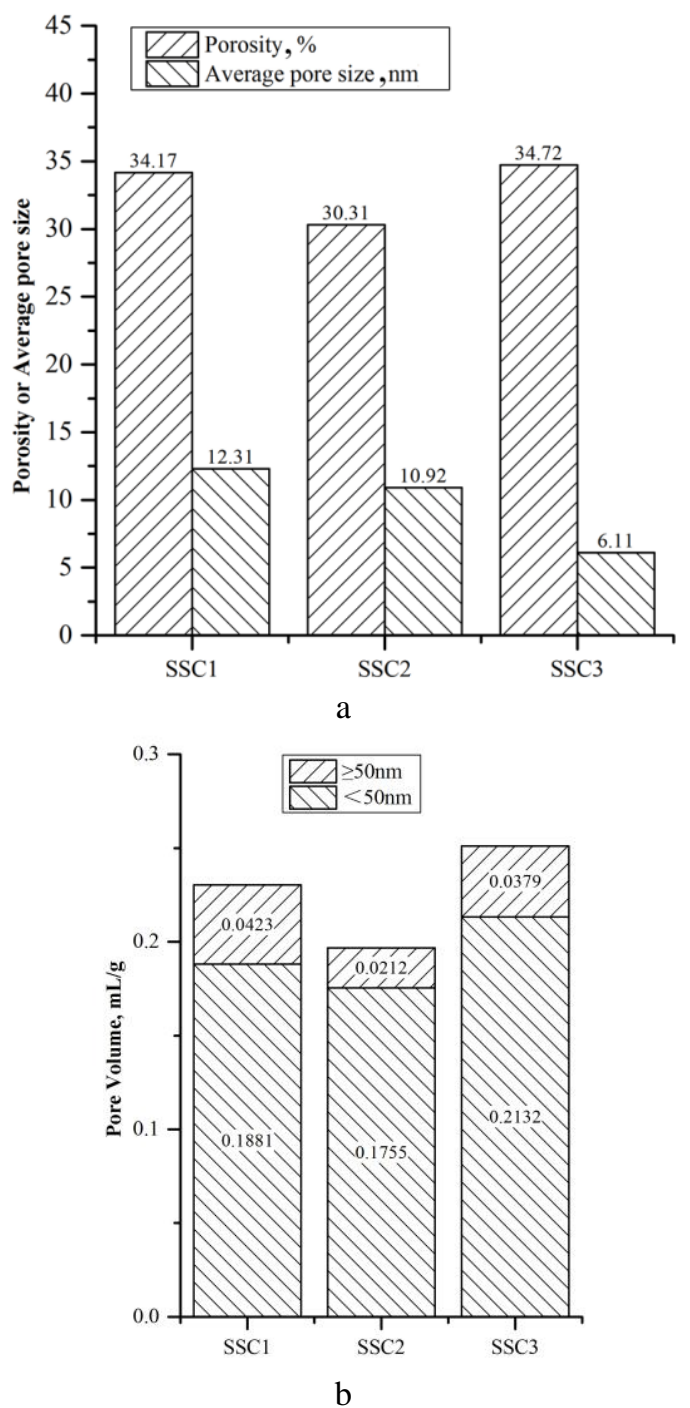

Fig. 4. The parameters of pore structure of SSC1, SSC2 and SSC 3

So for long curing age, burned at $500{ }^{\circ} \mathrm{C}$ for phosphogypsum is better than neutralized with $4 \%$ lime powder for specimen strength; for early curing time, neutralized with $4 \%$ lime powder for phosphogypsum is good for the hydration.

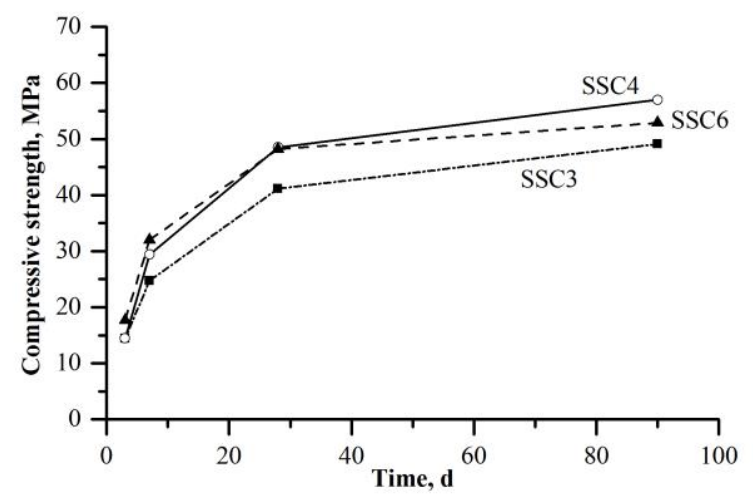

Fig. 5. Influence on compressive strength of phosphogypsum treatment methods in SSC

Fig. 6 shows the cumulative pore size distribution curves and the pore volume differential curves of SSC3,
SSC4 and SSC6. From Fig. 6, we can get the porosity, average pore size and the pore size classification with $50 \mathrm{~nm}$, and the results are shown in Fig. 7. Fig. 7 a shows that the average pore sizes of SSC4 is the smallest and results in the highest compressive strength development as shown in Fig. 5. Fig. $7 \mathrm{~b}$ shows that the pore volume of harmless pore with pore size smaller than $50 \mathrm{~nm}$ and harmful pore with pore size bigger than $50 \mathrm{~nm}$.
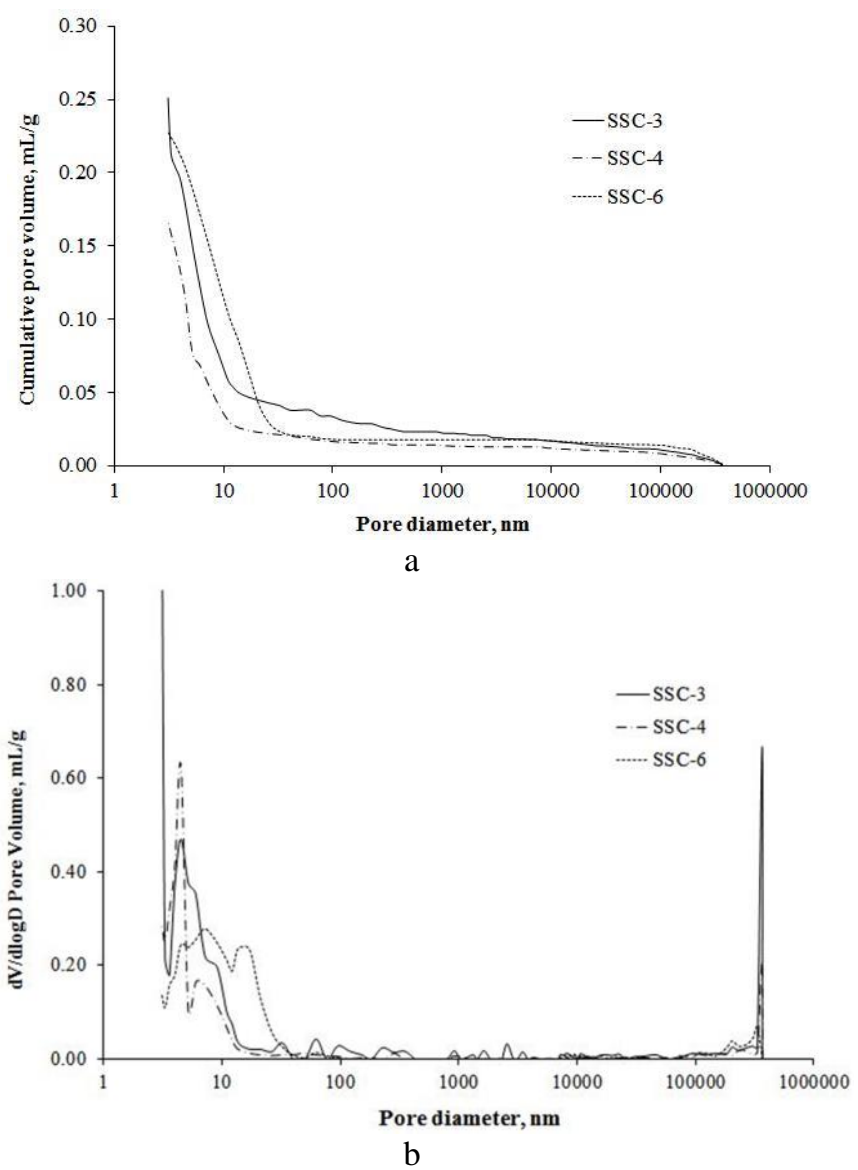

Fig. 6. The cumulative and differential pore size distribution curves of SSC3, SSC4 and SSC6

According to the formula Eq. $1, n_{\mathrm{SSC} 3}$ is $84.91 \%, n_{\mathrm{SSC} 4}$ is $0.1477 /(0.1477+0.0193)=88.44 \%$ and $n_{\mathrm{SSC} 6}$ is $0.208 /(0.208+0.0202)=91.15 \%$. As the result of value $n$, the highest value is $n_{\mathrm{SSC} 6}$, so the pore structure of SSC6 is relatively much denser than that of $\mathrm{SSC} 3$ and $\mathrm{SSC} 4$, and the strength development of SSC6 is the highest at early age, and a little lower than that of SSC4 in Fig. 5. Average pore size and the pore volume of harmless pore both can indicate the strength of paste.

Lime powder is used to neutralize the acid in phosphogypsum, to make the soluble phosphorus and soluble fluoride be the refractory material and eliminate their effect on the properties of cement. The addition of lime powder can make the system as the alkali gelation, and then the properties of slag can be inspired. Gelled material product binding together with phosphogypsum crystal makes it have certain mechanical strength [21]. Adding phosphogypsum in SSC will make it special density and the aperture are only a few microns, within the scope of the harmless pore. So the harmless pore to whole pore ratio of SSC6 is the biggest. 
Along with the temperature rise, the organic components in phosphogypsum are basically eliminated, the dehydration and crystal transformation of phosphogypsum happens in a few times and make the structure in a relaxation state. At the same time, at high temperature the $\mathrm{P}^{5-}$ adhered on the surface of the gypsum, diffuse inter to replace by $\mathrm{S}^{6-}$ to form phosphoric acid root and cause anionic absence, increase the calcium sulfate crystal structure defects, enhance sulfate effects, thus increase the intensity [22]. So SSC4 has the highest strength at later stage.
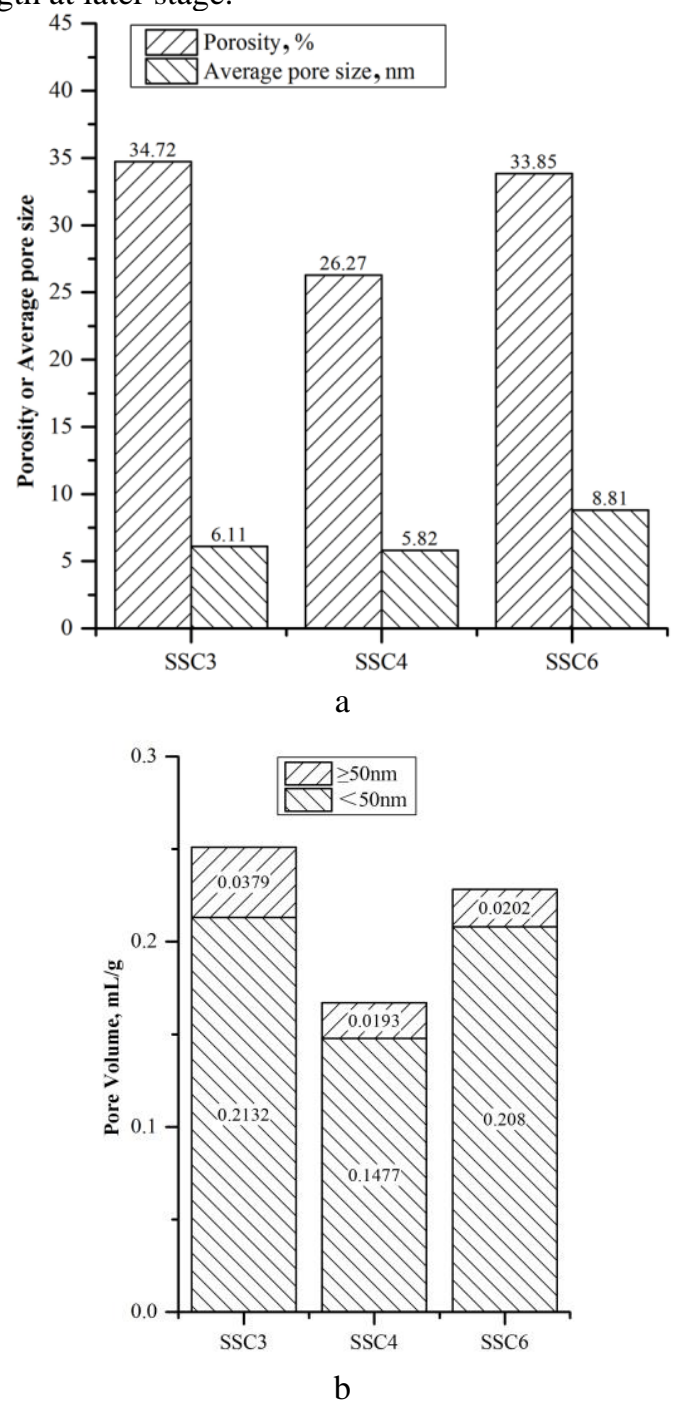

Fig. 7. The parameters of pore structure of SSC3, SSC4 and SSC6

\subsection{Effect of fineness}

The fineness of SSCs in this paper are 355, 445 and $518 \mathrm{~m}^{2} / \mathrm{kg}$, which are called SSC5, SSC6 and SSC7. The fineness is different, which will cause different reaction rate and compressive strength of SSCs at different hydration period.

Fig. 8 shows the compressive strength of SSCs with different fineness. The higher the fineness, the higher the strength, especially when it is from $355 \mathrm{~m}^{2} / \mathrm{kg}$ to $445 \mathrm{~m}^{2} / \mathrm{kg}$. The compressive strength of SSC5 is much lower than that of SSC6, especially at the age of 28 and
90 days. While the fineness reaches to $518 \mathrm{~m}^{2} / \mathrm{kg}$, the strength increases only a little.

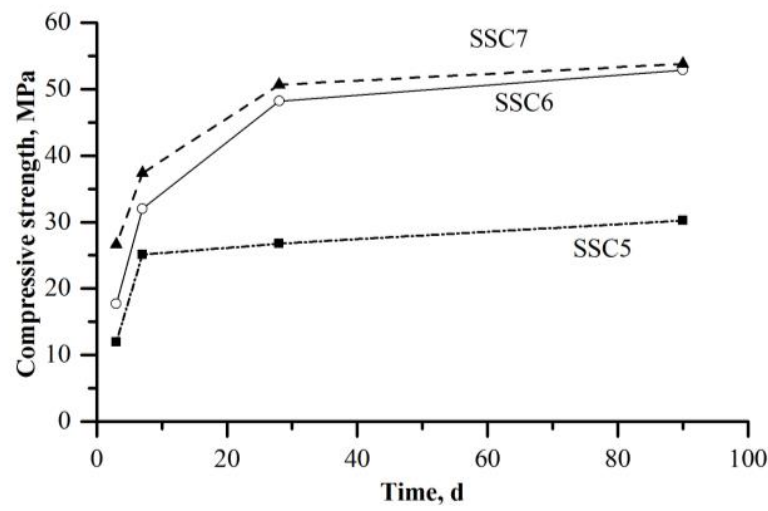

Fig. 8. Fineness influence on compressive strength of SSC

So the increase of fineness can make specimen strength increase, but not endlessly. In general, the small particle size benefits to the active excitation of materials. According to the views of nano materials, the specific surface area increases greatly with the decrease of pore size. The huge specific surface area makes the atomic number in the surface become more and serious mismatch, the key state surface can increase rapidly at the same time, make the surface atoms with high activity, appeared a lot of active center, unstable, it is easy to combine with other atoms. The bigger the specific surface area, therefore, the fuller the cement hydration, and there will produce more hydration products, such as ettringite and C-S-H [23], and improve the compressive strength.

Fig. 9 shows the cumulative pore size distribution curves and the pore volume differential curves of SSC5, SSC6 and SSC7.

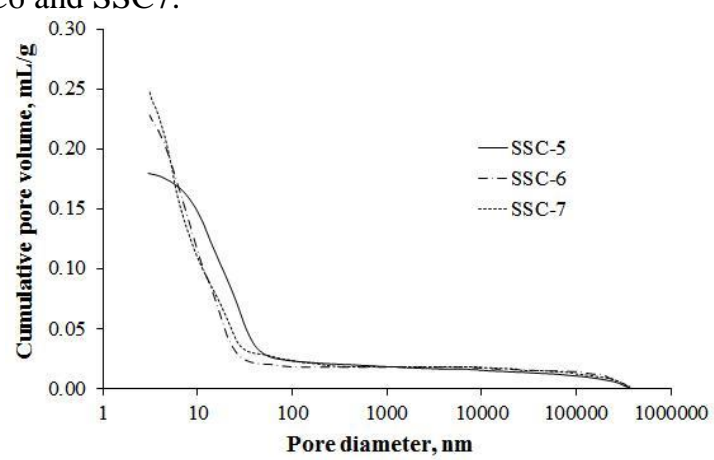

a

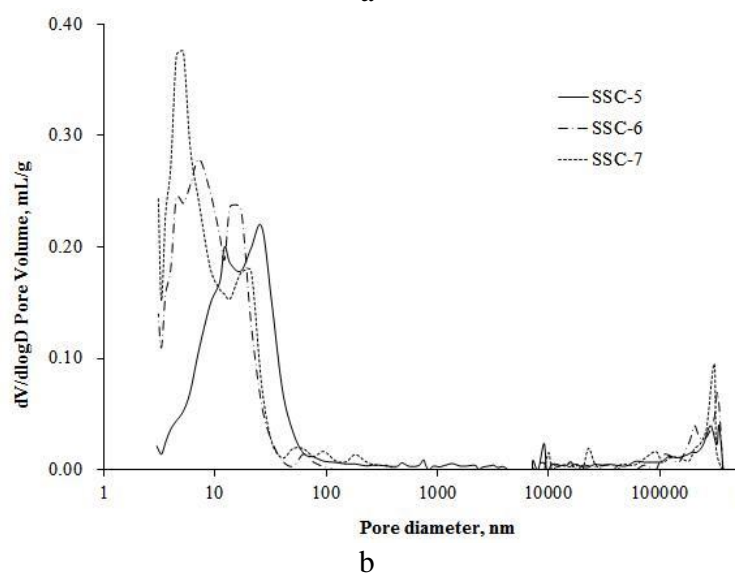

Fig. 9. The cumulative and differential pore size distribution curves of SSC5, SSC6 and SSC7 
From Fig. 9, we can get the porosity, average pore size and the pore size classification with $50 \mathrm{~nm}$ in Fig. 10.
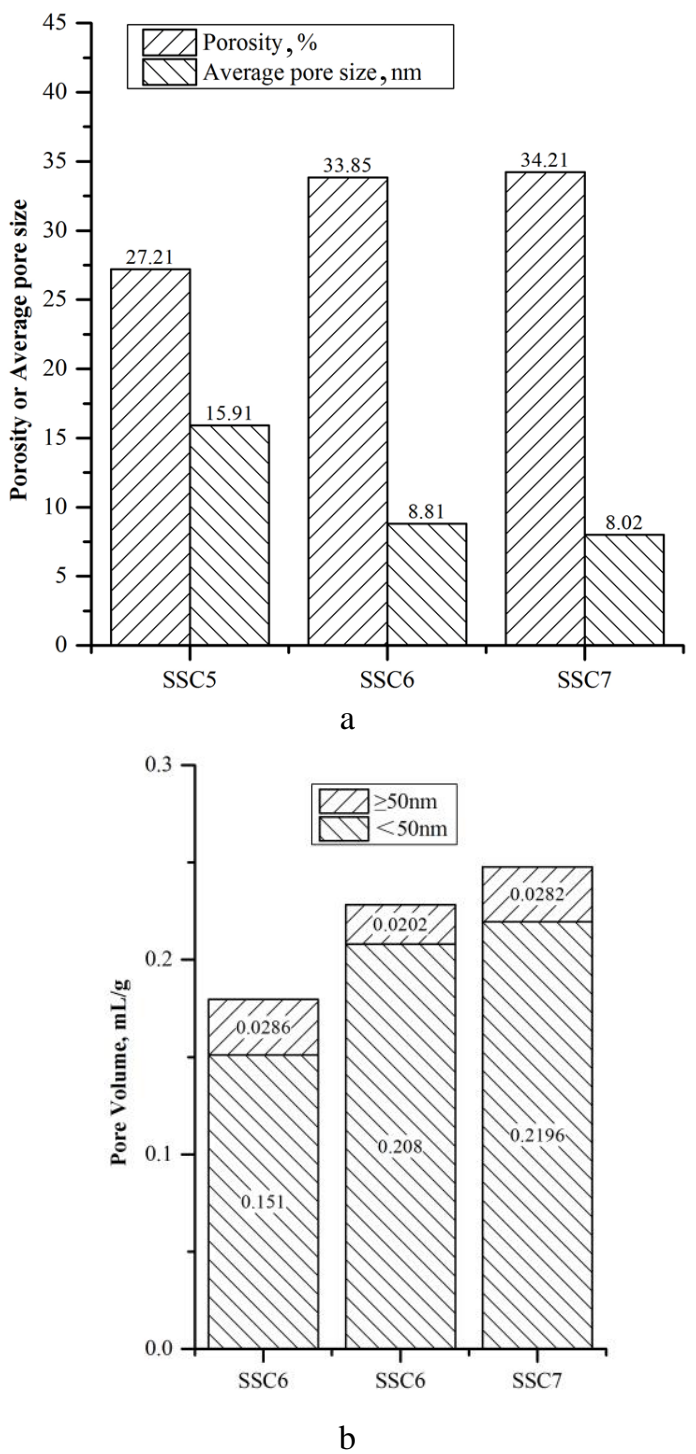

Fig. 10. The parameters of pore structure of SSC5, SSC6 and SSC7

From Fig.10 a, with the increase of fineness, the porosity increases and the average pore size decreases. The increasing porosity and decreasing average pore size can indicate the hydration degree and the increasing compressive strength of specimen. From Fig. 10 b, according to the Eq. $1, \quad n_{\mathrm{SSC} 5}$ is $0.151 /(0.151+0.0286)=84.08 \%, n_{\mathrm{SSC} 6}$ is $91.15 \%$ and $n_{\mathrm{SSC} 7}$ is $0.2196 /(0.2196+0.0282)=88.62 \%$. Although the average pore size of SSC7 is the smallest and the value $n_{\text {SSC6 }}$ is the biggest, the strength of them is similar, especially at the age of 90 days. When the fineness changes from $355 \mathrm{~m}^{2} / \mathrm{kg}$ to $445 \mathrm{~m}^{2} / \mathrm{kg}$, the strength increases a lot, especially at later stage, and the porosity increases and average pore size decreases. The higher fineness is, the quicker hydration rate is, which can generate more hydration products to uniform distribute in pores to decrease the average pore size. When the fineness changes from $445 \mathrm{~m}^{2} / \mathrm{kg}$ to $518 \mathrm{~m}^{2} / \mathrm{kg}$, the strength increases obviously at early age, while there is no difference at the age of 90 days. From the aspects of porosity and average pore size, there is no obvious difference between SSC6 and SSC7. When fineness is higher than $445 \mathrm{~m}^{2} / \mathrm{kg}$, there is little beneficial effects on the strength and pore structure.

\subsection{Effect of cement type}

Cement type can cause differences of compressive strength and pore structure. In this paper, ordinary Portland cement (PO), slag Portland cement (PS) and SSC (SSC6) are tested to compare the compressive strength and pore structure among them. The fineness of the three kinds of cements are about the same, 450,448 and $445 \mathrm{~m}^{2} / \mathrm{kg}$.

From Fig. 11, the compressive strength of PO is the biggest, while SSC6 is the smallest at every curing age.

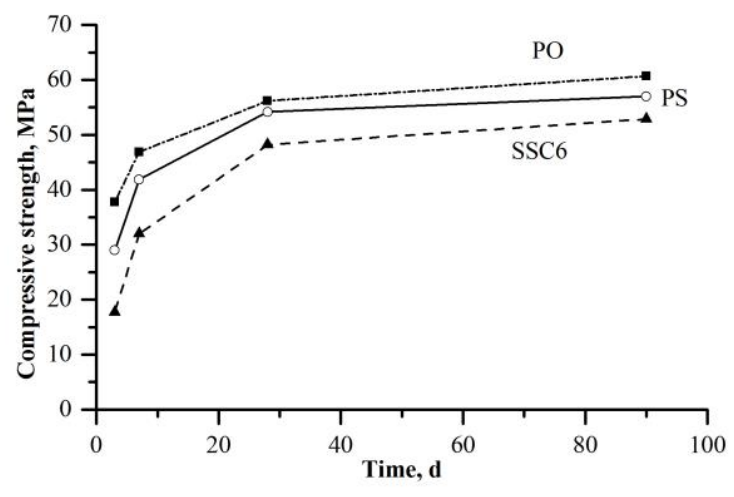

Fig. 11. Influence on compressive strength of cement type

At the curing age of 3 days, the strength of specimens from the high to the low are PO, PS and SSC6, which indicates that the reactive rate of PO is the highest at early age. While with the increase of curing age, the reactive rate of PO slows down gradually and is smaller than that of PS and SSC6. From the curing age from 7 days to 28 days, and from 28 days to 90 days, the reactive rate of SSC6 is the highest, which means that at late stage some components in SSC6 are activated and promote the development of strength.

Fig. 12 a shows the cumulative pore size distribution curves of PO, PS and SSC6, and Fig. $12 \mathrm{~b}$ shows the differential pore size distribution curves of the three cements. From the pore structure determination, the porosity, average pore size and the pore size classification with $50 \mathrm{~nm}$ are defined in Fig. 12, and the results are in Fig. 13. Fig. 13 a shows the porosity and average pore size of PO, PS and SSC6 at the age of 90 days. SSC6 has the smallest average pore size and the biggest porosity. In Fig. $13 \mathrm{~b}$, according to the Eq. $1, n_{\mathrm{PO}}$ is $0.0604 /(0.0604+0.0852)=41.48 \%, \quad n_{\mathrm{PS}}$ is $0.1881 /(0.1881+0.0423)=91.64 \%$ and $n_{\mathrm{SSC} 6}$ is $0.208 /(0.208+0.0202)=91.15 \%$. From the results, SSC6 has the highest ratio of the harmless pore to whole pore. Although the early strength of SSC6 is very low, from the pore structure at the age of 90 days, it must have good development of strength at late age as shown in Fig. 11. At early age, the ratio of clinker in PO is the highest, so it reacts quickly once meeting with water, as well as the highest compressive strength [24]. While at late age, the hydration degree of PO is much deeper than others, so some hydration products were wrapping over the surface 
of cement particles, which can retard the deeper hydration. On the contrary, the hydration degree of SSC6 at early age is not high, so in cement system some ions can easily get into slag particles or some active ions from slag particles dissolving out, which can accelerate hydration at late stage.

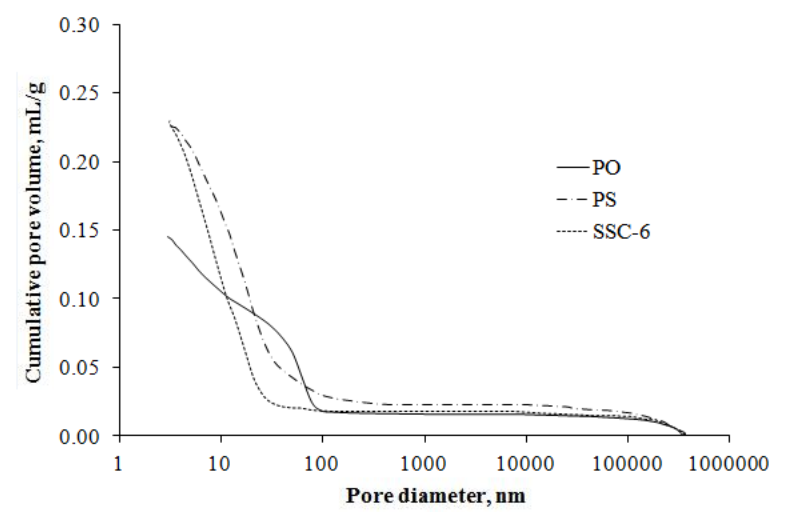

a

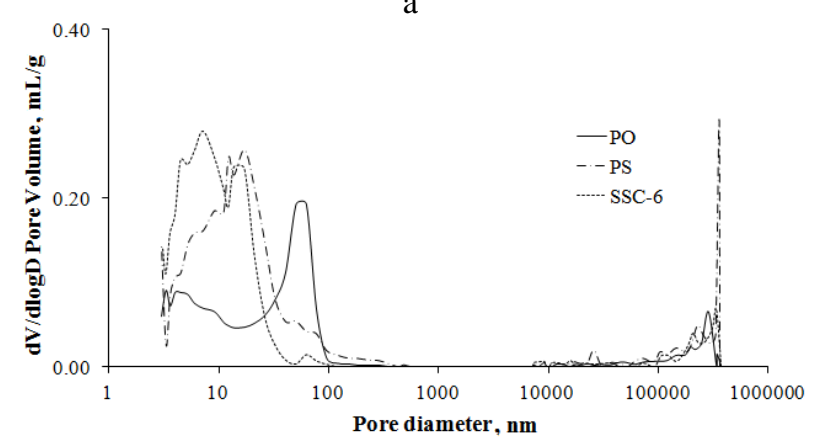

b

Fig. 12. The cumulative and differential pore size distribution curves of PO, PS and SSC6

\section{CONCLUSIONS}

1. Compared to SSCs containing anhydrite and dihydrate gypsum, phosphogypsum-based SSC performs better in compressive strength development especially at late age, which may be caused by the retarding effects of $\mathrm{P}_{2} \mathrm{O}_{5}$ in phosphogypsum and gypsum itself, which can slow the early hydration. While more hydration products have enough pores to generate, which improve the microstructure of paste.

2. For long curing age, burned at $500{ }^{\circ} \mathrm{C}$ for phosphogypsum in SSC is better than neutralized with $4 \%$ lime powder for specimen strength development.

3. The higher the fineness, the deeper the cement hydration, especially for early age, and there will produce more hydration products, such as ettringite and $\mathrm{C}-\mathrm{S}-\mathrm{H}$, and improve the compressive strength.

4. Compared to PO and PS, SSC containing phosphogypsum has the lowest strength at early age, while with the curing age growing, the strength growth rate of SSC6 is increasing.

5. The compressive strength of the SSC pastes mainly depends on the average pore size but porosity. The SSC pastes contain more harmless pore, which is beneficial for pore structure and strength.
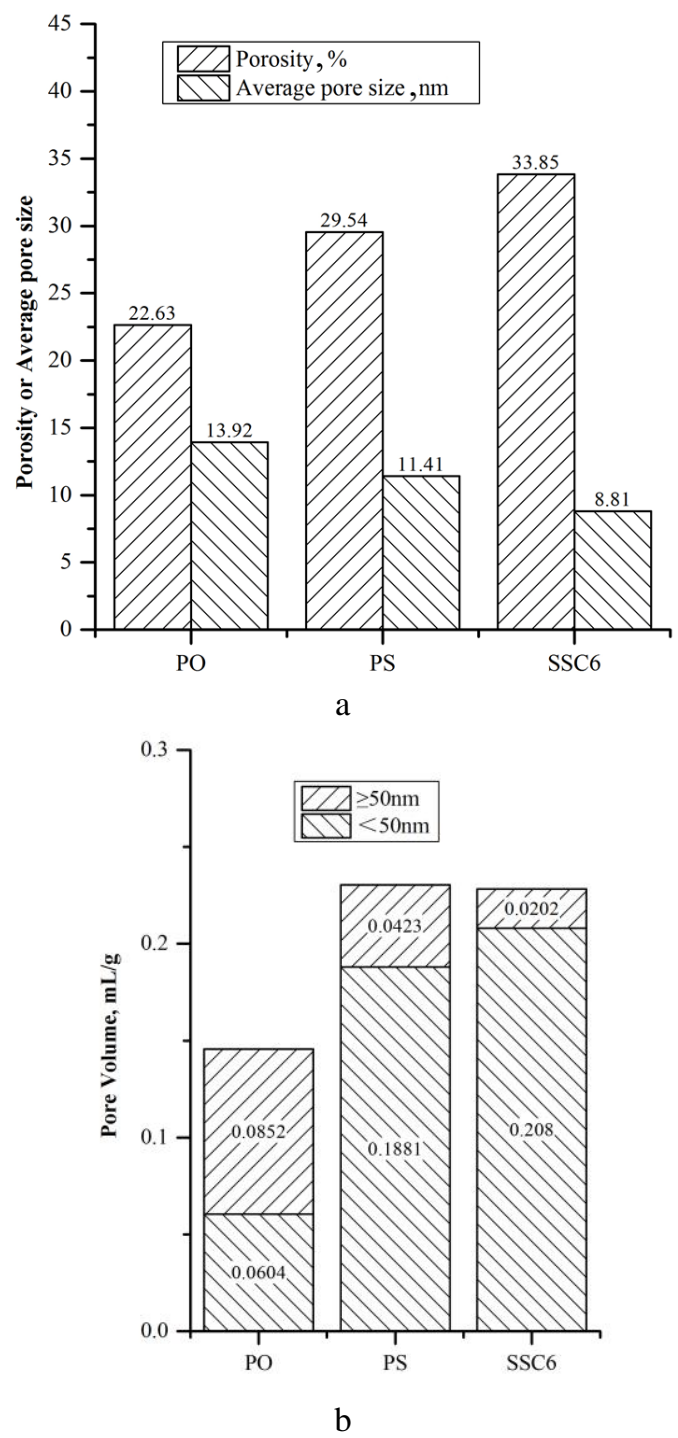

Fig. 13. The parameters of pore structure of PO, PS and SSC6

\section{Acknowledgments}

This Project is funded by the National Key R\&D Program of China (2016YFC0401907).

\section{REFERENCES}

1. Mehta, P.K. Reducing the Environmental Impact of Concrete Concrete International 23 (1) 2001: pp. $61-66$.

2. Worrell, E., Price, L., Martin, N., Hendriks, C., Meida, L.O. Carbon Dioxide Emissions from the Global Cement Industry Annual Review of Energy and Environment 26 2001: pp. 303-329. https://doi.org/10.1146/annurev.energy.26.1.303

3. Shammakh, M., Caruso, H., Elkamel, A., Croiset, E., Douglas, P.L. Analysis and Optimization of Carbon Dioxide Emission Mitigation Options in the Cement Industry American Journal of Environmental Sciences 4 (5) 2008: pp. $482-490$.

4. Ke, J., McNeil, M., Price, L., Khanna, N.Z., Zhou, N. Estimation of $\mathrm{CO}_{2}$ Emissions from China's Cement Production: Methodologies and uncertainties Energy Policy 57 2013: pp. $172-181$. https://doi.org/10.1016/j.enpol.2013.01.028 
5. Langan, B.W., Weng, K., Ward, M.A. Effect of Silica Fume and Fly Ash on Heat of Hydration of Portland Cement Cement and Concrete Research 32(10) 2002: pp. $1045-1051$.

https://doi.org/10.1016/S0008-8846(02)00742-1

6. Deschner, F. Hydration of Portland Cement with High Replacement by Siliceous Fly Ash Cement and Concrete Research 42 2012: pp. 1389-1400. https://doi.org/10.1016/j.cemconres.2012.06.009

7. Liu, S.H., Li, L.H. Influence of Fineness on the Cementitious Properties of Steel Slag Journal of Thermal Analysis and Calorimetry 117 (2) 2014: pp. 629-634. https://doi.org/10.1007/s10973-014-3789-0

8. Liu, S.H., Kong, Y.N., Wang, L. A Comparison of Hydration Properties of Cement-low Quality Fly Ash Binder and Cement-limestone Powder Binder Journal of Thermal Analysis and Calorimetry 116 (2) 2014: pp. 937-943. https://doi.org/10.1007/s10973-013-3576-3

9. Miyairi, H., Furukawa, R., Sato, K. The Influence of Chemical Composition of Granulated Blastfurnace Slag and Portland Cement Clinker of Various Portland Cements on Resistance to Seawater. CAJ Review, 29th Gen. Meeting: $73-85$.

10. Wang, L., Liu, S.H., Gao, Y.X., Yu, B.Y. Hydration Kinetics Model of Supersulfated Cement RILEM International Symposium on Concrete Modelling 12-14 October 2014, Beijing, China; 27-35.

11. Juenger, M.C.G., Winnefeld, F., Provis, J.L. Ideker, J.H. Advances in Alternative Cementitious Binders Cement and Concrete Research 41(12) 2011: pp. 1232-1243. https://doi.org/10.1016/j.cemconres.2010.11.012

12. Gruskovnjak, A., Lothenbach, B., Winnefeld, F. Hydration Mechanisms of Sulphated Slag Cement Cement and Concrete Research 38(7) 2008: pp. 983-992. https://doi.org/10.1016/j.cemconres.2008.03.004

13. Sarkar, S.L. Effect of Blaine Fineness Reversal on Strength and Hydration of Cement Cement and Concrete Research 20(4) 1990: pp. $398-406$.

https://doi.org/10.1016/0008-8846(90)90030-2

14. Bentz, D.P. Blending Different Fineness Cements to Engineer the Properties of Cement-based Materials Magazine of Concrete Research 62(5) 2010: pp. $327-338$. https://doi.org/10.1680/macr.2008.62.5.327

15. Hu, J., Ge, Z., Wang, K.J. Influence of Cement Fineness and Water-to-cement Ratio on Mortar Early-age Heat of
Hydration and Set Times Construction and Building Materials 50 (5) 2014: pp. 657-663.

https://doi.org/10.1016/j.conbuildmat.2013.10.011

16. Irassar, E.F., Violini, D., Rahhal, V.F., Milanesi, C., Trezza, M.A., Bonavetti, V.L. Influence of Limestone Content, Gypsum Content and Fineness on Early Age Properties of Portland Limestone Cement Produced by Inter-grinding Cement and Concrete Composites 33 (2) 2011: 192-200. https://doi.org/10.1016/j.cemconcomp.2010.10.001

17. Ramezanianpour, A.M., Hooton, R.D. A study on Hydration, Compressive Strength, and Porosity of Portland Limestone Cement Mixes Containing SCMs Cement and Concrete Composites 51 (1) 2014: pp. 1-13. https://doi.org/10.1016/j.cemconcomp.2014.03.006

18. Zeng, Q., Li, K.F., Chong, T.F., Dangla, P. Effect of Porosity on Thermal Expansion Coefficient of Cement Pastes and Mortars Construction and Building Materials 28 (4) 2012: pp. $468-475$. https://doi.org/10.1016/j.conbuildmat.2011.09.010

19. Matusinovic, T., Sipusic, J., Vrbos, N. Porosity-strength Relation in Calcium Aluminate Cement Pastes Cement and Concrete Research 33(11) 2003: 1801-1806. https://doi.org/10.1016/S0008-8846(03)00201-1

20. Alderete, N., Villagran, Y., Mignon, A. Pore Structure Description of Mortars Containing Ground Granulated BlastFurnace Slag by Mercury Intrusion Porosimetry and Dynamic Vapour Sorption Construction and Building Materials 145 2017: pp. 157-165. https://doi.org/10.1016/j.conbuildmat.2017.03.245

21. Jin, S.Q., Zhu, Y.M., Chen, L.Q. Study on Phosphorus Slag as RCC Admixture and its Applications HongShui River 31 (3) 2012: pp. 43-48.

22. Sun, D.S., Zhou, T.T., Wang, A.G., Deng, M., Tang, J.H. Research Status and Analysis of Cement-based Materials Mixed with Phosphorus Slag Materials Reviews 28 (7) 2014: pp. $96-100$.

23. Liu, S.H., Wang, L., Gao, Y.X., Yu, B.Y., Bai,Y. Comparing Study on Hydration Properties of Various Cementitious Systems Journal of Thermal Analysis and Calorimetry 118 (3) 2014: pp. 1483-1492. https://doi.org/10.1007/s10973-014-4052-4

24. Wu, B., Ye, G. Development of Porosity of Cement Paste Blended with Supplementary Cementitious Materials after Carbonation Construction and Building Materials 145 2017: pp. $52-61$. https://doi.org/10.1016/j.conbuildmat.2017.03.176 